Review

\title{
Control of Ochratoxin A Production in Grapes
}

\author{
María Lorena Ponsone ${ }^{1}$, María Laura Chiotta ${ }^{1}$, Juan Manuel Palazzini ${ }^{1}$, \\ Mariana Combina ${ }^{2}$ and Sofía Chulze ${ }^{1, *}$
}

1 Departamento de Microbiología e Inmunología, Facultad de Ciencias Exactas, Físico, Químicas y Naturales, Universidad Nacional de Río Cuarto, Ruta Nacional 601, (5800) Río Cuarto, Córdoba, Argentina; E-Mails: lponsone@exa.unrc.edu.ar (M.L.P.); mchiotta@exa.unrc.edu.ar (M.L.C.); jpalazzini@exa.unrc.edu.ar (J.M.P.)

2 Instituto Nacional de Tecnología Agropecuaria (INTA), Luján de Cuyo, Mendoza, Argentina; E-Mail: mcombina@mendoza.inta.gov.ar

* Author to whom correspondence should be addressed; E-Mail: schulze@exa.unrc.edu.ar; Tel.: +54-0358-4676-429; Fax: +54-0358-4676-231.

Received: 20 February 2012; in revised form: 24 April 2012 / Accepted: 25 April 2012 / Published: 14 May 2012

\begin{abstract}
Ochratoxin A (OTA) is a mycotoxin commonly present in cereals, grapes, coffee, spices, and cocoa. Even though the main objective of the food and feed chain processors and distributors is to avoid the extended contamination of plant-derived foods and animal feeds with mycotoxins, until now, complete OTA removal from foods and feedstuffs is not feasible. Prevention through pre-harvest management is the best method for controlling mycotoxin contamination. However, in the case that the contamination occurs after this stage, the hazards associated with OTA must be managed through post-harvest strategies. Due to the increasing number of fungal strains resistant to chemical fungicides and the impact of these pesticides on the environment and human health, maximum levels of chemical residues have been regulated in many products. Alternative methods are necessary to substitute or complement treatments with fungicides to control fungi under field or storage conditions. Yeasts are considered one of the most potent biocontrol agents due to their biology and non-toxic properties. Epiphytic yeasts are the major component of the microbial community on the surface of grape berries and they are evolutionarily adapted to this ecological niche. Nowadays, several yeast species included in different genera are considered as potential biocontrol agents to control both, growth of ochratoxigenic Aspergillus species and OTA accumulation.
\end{abstract}


Keywords: Ochratoxin A; prevention strategies; fungicides; biological control

\section{Introduction}

Ochratoxin A (OTA) is a mycotoxin commonly present in cereals, grapes, coffee, spices, cocoa and their processed products [1]. The toxin is produced by several species of the Aspergillus and Penicillium genera. OTA in cereals is mainly produced by $P$. verrucosum while OTA in grapes, coffee and cocoa is mainly produced by $A$. carbonarius [2]. In the last decade, OTA has received increased attention worldwide because of its hazard to human and animal health [3]. Due to this toxicity, the International Agency for Research on Cancer (IARC) has classified OTA as a group 2B carcinogen [4]. OTA can contaminate a wide variety of foodstuffs and maximum permitted levels have been established by the EU and other countries to reduce the risk of human exposure [5].

The critical factors that affect fungal growth during farming, harvesting and storage are temperature, moisture content and the period that the commodity remains under adverse conditions. Mycotoxin biosynthesis is also affected by a wide range of factors, broadly classified into physical, biological and chemical, and by interactions involving these factors. Temperature, and humidity are key factors that interact to affect mycotoxin biosynthesis. The knowledge of the factors involved in OTA production and their interaction will allow the prediction and prevention of OTA contamination [6-8]. Also it is possible to detect OTA without the presence of the ochratoxigenic species since processing or environmental changes can inactivate the fungal spores but not alter the toxin that remains in the substratum [9]

Even though the main objective of the food and feed chain providers is to avoid the extended contamination of plant-derived foods and animal feeds with OTA, until now, complete OTA removal from foods and feedstuffs is not feasible [10]. Many efforts are being made to achieve OTA reduction. Prevention through pre-harvest management is the best method for controlling mycotoxin contamination [9,11]. However, if contamination occurs after this stage, OTA hazards must be managed through post-harvest strategies. The methods currently employed to prevent OTA contamination in grapes are reviewed.

\section{Chemical Control of OTA Production: Fungicides and Antioxidants}

Ochratoxigenic species can colonize damaged parts of plants. Therefore, it is logical to protect grapes from mechanical and insect damages. Although damaged grapes can be removed, inoculum sources such as weeds, agricultural residues or dirty farming materials also have to be minimized to reduce contamination $[10,12]$

The use of chemical compounds is a very attractive strategy to prevent mycotoxin production [13]. In the case of pesticides, the implications for mycotoxin production need to be considered. It has been reported that some fungicides influence positively or negatively OTA production [14]. Lo Curto et al. [15] observed that application of some pesticides such as Azoxystrobin (a strobilurin derivative) or Dinocap (a dinitrophenyl derivative) in combination with sulfur effectively decreased OTA content in wines. In contrast, it was observed that pesticides such as Carbendazim and Chorus 
were ineffective in controlling sour rot caused by Aspergillus section Nigri. However, the application of another pesticide, Switch, led to a significant reduction in the incidence of black aspergilli on grapes. The fungicide Switch contains cyprodinil and fludioxonil which belong to the pyrimidine and pyrrolnitrin classes of fungicides, respectively. Since the fungicide Chorus contains cyprodinil and was ineffective against aspergilli, it was concluded that fludioxonil was the active ingredient of Switch [16]. The observation that fludioxonil can be used against black aspergilli is not surprising since pyrrolnitrin was previously found to be effective against black aspergilli [17]. In another study carried out in France [18], the fungicides Switch, Scala (containing the pyrimidine fungicide pyrimethanil) and Mikal (containing fosetyl-Al and the dicarboximide folpel) were effective for lowering fungal colonization and OTA content in wines. Moreover, in vitro studies done by Belli et al. [19] with 26 fungicides showed that fungicides that stopped $A$. carbonarius growth also inhibited OTA synthesis. In general, fungicides that contained copper or strobilurins reduced both, growth and OTA production, contrary to sulfur fungicides. Among the fungicides that inhibited $A$. carbonarius growth in synthetic medium, cyprodinil seemed to be the most effective active ingredient to stop fungal growth when reduced doses were tested. When these fungicides were tested on grapes, the effect was similar to that observed on synthetic medium [19]. It is important to remark that fungicides must be applied with care since some of them, such as carbendazim, have been found to reduce fungal flora but stimulate OTA production [15].

Another strategy to reduce fungal growth and mycotoxin production is the use of antioxidants such as vanillic acid or 4-hydroxybenzoic acid [20] and essential oils extracted from plants such as Thymus vulgaris or Aframomum danielli [11,21], which affected both, fungal growth and OTA synthesis. From a human health perspective, the use of antioxidants as antimicrobial agents is allowed by the US Food and Drug Administration (FDA) and regarded as safe (GRAS) chemicals. Even though these antioxidants have not been tested on dried vine fruits, some studies have shown that these compounds have a protective action in food since they could maintain organoleptic properties [22-25]. This could be an interesting option for commodities that requires long storage periods, such as dried vine fruits.

Trans-resveratrol (3,5,4-trihydroxystilbene) is an antioxidant compound naturally produced in a huge number of plants, including grapes, being the major component of the phytoalexin response of the plant. It accumulates in vine leaves and grape skin in response to various fungal infections, UV radiation, or chemicals [26-28], and it has been found in wines in varying concentrations depending on viticultural and enological practices [29].

Analytical interest in trans-resveratrol was attributed to its natural pesticide properties. A recent study showed that trans-resveratrol is fungitoxic at physiological concentrations against B. cinerea [30]. However trans-resveratrol has also been proven to enhance the resistance of vine plants to other pathogens, such as Plasmopara viticola [31], Phomopsis viticola [32], or Rhizopus stonifer [33]. Recently, Perrone et al. [34] detected a positive correlation in wine samples from southern Italy, between levels of OTA and total stilbenes as well as between OTA and total resveratrols and between OTA and total piceids, suggesting that OTA production stimulates stilbenes synthesis. This rather unspecific antifungal character and the selective accumulation of trans-resveratrol in grape skin make it a good candidate as a natural pesticide against pathogen attack for improving the natural resistance of grapes to fungal infection. In addition, because of its antioxidant properties, trans-resveratrol can also have positive effects on fruit conservation during 
storage. As a consequence, both endogenous enhancement and exogenous application could be exploited to reduce grape spoilage.

It is important to take into account that the determination of optimal application doses of antifungal substances is very important, because high levels could produce undesirable effects on the grain organoleptic properties and on its processed products, causing a negative economic impact. On the other hand, sub-inhibitory doses together with inadequate distribution of chemicals, especially at low $\mathrm{a}_{\mathrm{W}}$ values, could cause fungal sporulation, growth and secondary metabolism stimulation, increasing mycotoxin production [35].

\section{Biocontrol as an Ecofriendly Strategy}

Although chemicals have been commonly used to reduce fungal proliferation and mycotoxin production under field conditions, nowadays a strict legislation about their use has been established in the European Union, due to the increasing number of resistant fungal strains and the impact of fungicides on the environment and human health [36]. Maximum residue levels of pesticides have been regulated in many products, including grapes [37]. Therefore, alternative methods are necessary to substitute or complement fungicide treatments to control toxigenic fungi at pre- and postharvest stages.

Biological control using antagonist microorganisms has been proposed for a long time as a good option to control plant pathogens [38]. One of the advantages of biocontrol is that it could be used together with fungicides reducing their levels in order to decrease fungal growth [39-41].

Yeasts are considered one of the most potent biocontrol agents due to their biology and non toxic properties [42]. The mechanism most probably involved in filamentous fungi biocontrol by yeast is competition. Competition among microorganisms for essential factors, such as nutrients and space, is expected to have a dramatic effect on the secondary metabolism of filamentous fungi $[41,43]$. On the other hand, parasitism and production of fungal growth inhibiting compounds have been also described $[42,44]$. Nowadays, several yeast species included in different genera are considered potential biocontrol agents towards ochratoxigenic Aspergillus [45-48]. Epiphytic yeasts are the major component of the microbial community on the surface of grape berries and they are evolutionarily adapted to this ecological niche [49]. Yeasts, indeed, can be effective biocontrol agents due to their capacity to colonize grapes and compete for space and nutrients with other microorganisms [50]. In this direction, Zahavi et al. [48] selected two antagonistic yeast isolates, Candida guillermondii and Acremonium cephalosporium, and showed that they were efficient in reducing decay caused by Botrytis, Rhizopus and Aspergillus. In addition, Bleve et al. [45] showed that Issatchenkia orientalis have a strong antagonistic action against ochratoxigenic species; moreover, they also indentified an isolate of Metschnikowia pulcherrima and an isolate of Candida incommunis that also significantly reduced $A$. niger and $A$. carbonarius growth both in vitro and in situ. In another study carried out by Dimakopoulou et al. [46], it was demonstrated that one strain of Aureobasidium pullulans was effective in reducing sour rot infection, A. carbonarius presence on berries at harvest and OTA contamination in must. Recently, Ponsone et al. [47] described two epiphytic strains of Lanchancea thermotolerans that were able to control the growth and OTA accumulation of ochratoxigenic fungi both "in vitro" and "in situ". The data reported until now indicate that the yeasts that occur naturally on 
grapes, are promising ecological fungicides, because they can survive and colonize grape berries in the vineyards and also maintain the equilibrium of the natural environment.

In order to prevent a pathogen from establishing itself on the plant, it is important to have the biological control agent on the fruit surface before the arrival of the propagules of the pathogen [51]. This can be achieved either through frequent applications, or by using strains that can survive on the field [52].

The future use of biological control agents for controlling ochratoxigenic fungi and ochratoxin production will depend on the cost production and the field effectiveness of the formulated product. Therefore, the optimization of biocontrol efficacy also depends on survival and colonization of biological control agents in wounded and unwounded fruit surfaces and in the presence of low quantities of fungicides applied separately or in combination with microbial antagonists. Moreover, the widespread diffusion of fungal pathogens resistant to fungicides used for a long time in the field and/or in packinghouses (e.g., benzimidazoles), has led to the need of assessing the compatibility and efficacy of biological control agents with new and recently developed fungicides [53].

The application of biocontrol agents during vintage should not affect the organoleptic characteristics of the harvested grapes. To avoid the changes on the harvested grapes the application of $\mathrm{CuSO}_{4}$ can be done 20 days prior to harvest. For grapes used for wine production, a normal practice in the vinification process is the addition of sulfur dioxide (sulfiting step), which leads to the inhibition of indigenous yeasts ensuring an effective seeding with the chosen commercial yeast strain for the alcoholic fermentation. Also, during the final step of wine production, a racking step takes place that eliminates the solids present in the wine, including yeast cells, yeast lees, and small solids [54].

In conclusion, an integrated strategy based on the combination of biological control agents with natural compounds or reduced dosage of fungicides appears to be one of the most reliable options for large-scale utilization of microbial antagonists in the control of ochratoxigenic fungi and reduction of the entry of OTA to the food chains $[55,56]$.

\section{Conflict of Interest}

The authors declare no conflict of interest.

\section{References}

1. Speijers, G.J.A.; van Egmond, H.P. Worldwide Ochratoxin A Levels in Food and Feeds. In Human Ochratoxicosis and Its Pathologies; Creppy, E.E., Dirheimer, M., Castegnaro, G., Eds.; John Libbey Euroto Ltd.: Montrouge, France, 1993; pp. 85-100.

2. Cabañes, F.J.; Accensi, F.; Bragulat, M.R.; Abarca, M.L.; Castellá, G.; Minguez, S.; Pons, A. What is the source of ochratoxin A in wine? Int. J. Food Microbiol. 2002, 79, 213-215

3. Mantle, P.G. Risk assessment and the importance of ochratoxins. Int. Biodeterior. Biodegrad. 2002, 50, 143-146.

4. IARC International Agency for Research on Cancer. Some Naturally Occurring Substances: Food Items and Constituents: Heterocyclic Aromatic Amines and Mycotoxins. In IARC Monographs on the Evaluation of the Carcinogenic Risks to Humans; IARC: Lyon, France, 1993; Volume 56, pp. 489-521. 
5. European Commission. Commission regulation (EC) No. 123/2005 of 26 January 2005 amending regulation (EC) No. 466/2001 as regards ochratoxin A. Off. J. Eur. Union 2005, L25, 3-5.

6. Abramson, D. Measurement of ochratoxin A in barely extracts by liquid chromatography mass spectrometry. J. Chromatogr. 1987, 391, 315-320.

7. Astoreca, A.; Magnoli, C.; Barberis, C.; Combina, M.; Chiacchiera, S.M.; Dalcero, A. Ochratoxin A production in relation to ecophysiological factors by Aspergillus section Nigri strains isolated from different substrates in Argentina. Sci. Total Environ. 2007, 388, 16-23.

8. Suárez-Quiroz, M.; González-Rios, O.; Barel, M.; Guyot, B.; Schorr-Galindo, S.; Guiraud, J.P. Study of ochratoxin A-producing strains in coffee processing. Int. J. Food Sci. Technol. 2004, 39, 501-507.

9. Amézqueta, S.; González-Peñas, E.; Murillo-Arbizu, M.; López de Cerain, A. Ochratoxin A decontamination: A review. Food Control 2009, 20, 326-333.

10. Codex Alimentarius Commission. Codex Alimentarius Commission Alinorm 03/12 Appendix XII. Technical Report for the 34th Session of the Codexcommittee on Food Additives and Contaminants; Codex Alimentarius Commission: Rome, Italy, 2003; pp. 100-104.

11. Kabak, B.; Dobson, A.D.W. Biological strategies to counteract the effects of mycotoxins. J. Food Protect. 2009, 72, 2006-2016.

12. Park, D.L.; Njapau, H.; Boutrif, E. Minimising Risks Posed by Mycotoxins Utilising the HACCP Concept. In Proceedings of Third Joint FAO/WHO/UNEP International Conference on Mycotoxins, Tunis, Tunisia, 3-6 March 1999; pp. 1-13. Available online: ftp://ftp.fao.org/ es/esn/food/myco8b.pdf (accessed on 28 April 2012).

13. Riley, R.T.; Norred, W.P. Mycotoxin prevention and decontamination, corn-A case study. In Atti Third Joint FAO/WHO/UNEP international conference on mycotoxins, Tunis, Tunisia, 3-6 March 1999; pp. 1-11. Available online: ftp://ftp.fao.org/es/esn/food/myco6b.pdf (accessed on 28 April 2012).

14. Medina, A.; Mateo, R.; Valle-Algarra, F.; Mateo, E.M.; Jiménez, M. Effect of carbendazim and physicochemical factors on the growth and ochratoxin A production of Aspergillus carbonarius isolated from grape. Int. J. Food Microbiol. 2007, 119, 230-235.

15. Lo Curto, R.; Pellicano, T.; Vilasi, F.; Munafo, P.; Dugo, G. Ochratoxin A occurrence in experimental wines in relationship with different pesticide treatments of grapes. Food Chem. 2004, 84, 71-75.

16. Tjamos, S.E.; Antoniou, P.P.; Kazantzidou, A.; Antonopoulos, D.F.; Papageorgiou, I.; Tjamos, E.C. Aspergillus niger and A. carbonarius in Corinth raisin and wine-producing vineyards in Greece: Population composition, ochratoxin A production and chemical control. J. Phytopathol. 2004, 152, 250-255.

17. Chernin, L.; Brandis, A.; Ismailov, Z.; Chet, I. Pyrrolnitrin production by an Enterobacter agglomerans strain with a broad spectrum of antagonistic activity towards fungal and bacterial phytopathogens. Curr. Microbiol. 1996, 32, 208-212.

18. Molot, B.; Solanet, D. Ochratoxine: Prévention du risque. In Etude au vignoble de fongicides actifs contre Aspergillus carbonarius incidences sur la présence aux vendanges, Proceedings of Les Entretiens Viti-Vinicoles Rhone-Mediterranée, Nimes, France, 16 April 2003; pp. 18-21. 
19. Bellí, N.; Marín, S.; Sanchis, V.; Ramos, A.J. Impact of fungicides on Aspergillus carbonarius growth and ochratoxin A production on synthetic grape-like medium and on grapes. Food Addit. Contam. 2006, 23, 1021-1029.

20. Palumbo, J.D.; O’Keeffe, T.L.; Mahoney, N.E. Inhibition of ochratoxin A production and growth of Aspergillus species by phenolic antioxidant compounds. Mycopathologia 2007, 164, 241-248.

21. Aroyeun, S.O.; Adegoke, G.O. Reduction of ochratoxin A (OTA) in spiked cocoa powder and beverage using aqueous extracts and essential oils of Agramomum danielli. Afr. J. Biotechnol. 2007, 6, 612-616.

22. Nguefack, J.; Nguikwie, S.K.; Fotio, D.; Dongmo, B.; Amvam Zollo, P.H.; Leth, V.; Nkengfack, A.E.; Poll, L. Fungicidal potential of essential oils and fractions from Cymbopogon citratus, Ocimum gratissimum and Thymus vulgaris to control Alternaria padwickii and Bipolaris oryzae, two seed-borne fungi of rice (Oryza Sativa L.). J. Essent. Oil Res. 2007, 19, 581-587.

23. Valle Vega, P.; Florentino, B.L. Toxicología de Alimentos. Instituto Nacional de Salud Publica: México, México, 2000; pp. 132-137, 149-150.

24. Passone, M.A.; Resnik, S.L.; Etcheverry, M.G. In vitro effect of phenolic antioxidants on germination, growth and aflatoxin B1 accumulation by peanut Aspergillus section Flavi. J. App. Microbiol. 2005, 99, 682-691.

25. Barberis, C.; Astoreca, A.; Fernández-Juri, M.G.; Chulze, S.; Magnoli, C.; Dalcero, A. Use of propyl paraben to control growth and ochratoxin A production by Aspergillus section Nigri species on peanut meal extract agar. Int. J. Food Microbiol. 2009, 136, 133-136.

26. Langcake P. Disease resistance of Vitis spp. and the production of the stress metabolites resveratrol, epsilon-viniferin, alpha-viniferin and pterostilbene. Physiol. Plant Pathol. 1981, 18, 213-226.

27. Jeandet, P.; Bessis, R.; Sbaghi, M.; Meunier, P. Production of the phytoalexin resveratrol by grapes as a response to Botrytis attack under natural conditions. J. Phytopathol. 1995, 143, 135-139.

28. Adrian, M.; Jeandet, P.; Veneau, J.; Weston, L.A.; Bessis, R. Biological activity of resveratrol, a stilbenic compound from grapevines, against Botrytis cinerea, the causal agent for gray mold. J. Chem. Ecol. 1997, 23, 1689-1702.

29. Soleas, G.J.; Dam, J.; Carey, M.; Goldberg, D.M. Toward the fingerprinting of wines: Cultivar-related patterns of polyphenolic constituents in Ontario wines. J. Agric. Food Chem. 1997, 45, 3871-3880.

30. Adrian, M.; Rajaei, H.; Jeandet, P.; Veneau, J.; Bessis, R. Resveratrol oxidation in Botrytis cinerea conidia. Phytopathology 1998, 88, 472-476.

31. Dai, G.H.; Andary, C.; Mondolot-Cosson, L.; Boubals, D. Histochemical studies on the interaction between three species of grapevine, Vitis vinifera, $V$. rupestris and $V$. rotundifolia and the downy mildew fungus, Plasmopara viticola. Physiol. Mol. Plant Pathol. 1995, 46, 177-188.

32. Hoos, G.; Blaich, R.J. Influence of resveratrol on germination of conidia and mycelial growth of Botrytis cinerea and Phomopsis viticola. J. Phytopathol. 1990, 129, 102-110.

33. Sarig, P.; Zutkhi, Y.; Monjauze, A.; Lisker, N.; Ben-Arie, R. Phytoalexin elicitation in grape berries and their susceptibility to Rhizopus stolonifer. Physiol. Mol. Plant Pathol. 1997, 50, $337-347$. 
34. Perrone, G.; Nicoletti, I.; Pascale, M.; De Rossi, A.; De Girolamo, A.; Visconti, A. Positive correlation between high levels of ochratoxin A and resveratrol-related compounds in red wines. J. Agric. Food Chem. 2007, 55, 6807-6812.

35. Marin, S.; Guynot, M.E.; Neira, P.; Bernadó, M.; Sanchis, V.; Ramos, A.J. Risk assessment of the use of sub-optimal levels of weak-acid preservatives in the control of mould growth on bakery products. Int. J. Food Microbiol. 2002, 79, 203-211.

36. De Costa, P.; Bezerra, P. Fungicides: Chemistry, Environmental Impact and Health Effects; Nova Biomedical: Waltham, UK, 2009.

37. European Commission. Commission regulation (EC) No. 299/2008 amending regulation (EC) No. $396 / 2005$ on maximum residue levels of pesticides in or on food and feed of plant and animal origin, as regards the implementing powers conferred on the Commission. Off. J. Eur. Union 2008, 97, 67-71.

38. Wilson, C.L.; Wisniewski, M.E. Biological control of postharvest diseases of fruits and vegetables: An emerging technology. Annu. Rev. Phytopathol. 1989, 27, 425-441.

39. Janisiewicz, W.J.; Korsten, L. Biological control of postharvest diseases of fruits. Annu. Rev. Phytopathol. 2002, 40, 411-441.

40. Ippolito, A.; Nigro, F.; Schena, L. Control of postharvest diseases of fresh fruits and vegetables by preharvest application of antagonistic microorganisms; In Crop Management and Postharvest Handling of Horticultural Products: Disease and Disorders of Fruits and Vegetables; Dris, R., Niskanen, R., Jain, S.M., Eds.; Science Publisher Inc.: Enfield, NH, USA, 2004; pp. 1-30.

41. Spadaro, D.; Gullino, M.L. State of the art and future prospects of the biological control of postharvest fruit diseases. Int. J. Food Microbiol. 2004, 91, 185-194.

42. Pimenta, R.S.; Morais, P.B.; Rosa, C.A.; Correa, A. Utilization of Yeast in Biological Control Programs; In Yeast Biotechnology: Diversity and Applications; Satyanarayana, T., Kun, G., Eds.; Springer: Berlin, Germany, 2009.

43. Zhou, T.; Yu, H.; Errampali, D. Strategies for Biological Control of Fungal Diseases of Temperate Fruits; In Biological Control of Plant Diseases; Chincholkar, S.B., Mukerji, K.G., Eds.; Haworth Press: New York, NY, USA, 2007; pp. 239-277.

44. El-Tarabily, K.A.; Sivasithamparam, K. Potential of yeasts as biocontrol agents of soil-borne fungal plant pathogens and as plant growth promoters. Mycoscience 2006, 47, 25-35.

45. Bleve, G.; Grieco, F.; Cozzi, G.; Logrieco, A.; Visconti, A. Isolation of epiphytic yeast with potential for biocontrol of Aspergillus carbonarius and A. niger on grape. Int. J. Food Microbiol. 2006, 108, 204-209.

46. Dimakopoulou, M.; Tjamos, S.E.; Antoniou, P.P.; Pietri, A.; Battilani, P.; Avramidis, N.; Markakis, E.A.; Tjamos, E.C. Phyllosphere grapevine yeast Aureobasidium pullulans reduces Aspergillus carbonarius (sour rot) incidence in wine-producing vineyards in Greece. Biol. Control 2008, 46, 158-165.

47. Ponsone M.L.; Chiotta, M.L.; Combina M.; Dalcero, A.; Chulze, S. Biocontrol as a strategy to reduce the impact of ochratoxin A and Aspergillus section Nigri in grapes Int. J. Food Microbiol. 2011, 151, 70-77. 
48. Zahavi, T.; Cohen, L.; Weiss, B.; Schena, L.; Daus, A.; Kaplunov, T.; Zutkhi, J.; Ben-Arie, R.; Droby, S. Biological control of Botrytis, Aspergillus and Rhizopus rots on table and wine grapes in Israel. Postharvest Biol. Technol. 2000, 20, 115-124.

49. Beech, F.W.; Davenport, R. The Role of Yeast in Cidermaking; In The Yeasts; Rose, A.H., Harrison, J.S., Eds.; Academic Press: London, UK, 1970; pp. 73-139.

50. McLaughlin, R.J.; Wisniewski, M.E.; Wilson, C.L.; Chalutz, E. Effects of inoculum concentration and salt solutions on biological control of postharvest diseases of apple with Candida spp. Phytopathology 1990, 80, 456-461.

51. Fokkema, N.J. Biological control of fungal plant diseases. Entomophaga 1996, 41, 333-342.

52. Benbow, J.M.; Sugar, D. Fruit surface colonization and biological control of postharvest diseases of pear by preharvest yeast applications. Plant Dis. 1999, 83, 839-844.

53. Lima, G.; Castoria, R.; DeCurtis, F.; Raiola, A.; Ritieni, A.; DeCicco, V. Integrated control of blue mould using new fungicides and biocontrol yeasts lowers levels of fungicide residues and patulin contamination in apples. Postharvest Biol. Technol. 2011, 60, 164-172.

54. Ribereau-Gayon, P.; Dubourdieu, D.; Doneche, B.; Lonvaud, A. Handbook of Enology: The Microbiology of Wine and Vinifications, 2nd ed.; John Wiley \& Sons, Ltd.: Hoboken, NJ, USA, 2006.

55. Lima, G.; De Curtis, F.; De Cicco, V. Interaction of microbial biocontrol agents and fungicides in the control of postharvest diseases. Stewart Postharvest Rev. 2008, 1, 1-7.

56. Droby, S.; Wisniewski, M.; Macarisin, D.; Wilson, C. Twenty years of postharvest biocontrol research: Is it time for a new paradigm? Postharvest Biol. Technol. 2009, 52, 137-145.

(C) 2012 by the authors; licensee MDPI, Basel, Switzerland. This article is an open access article distributed under the terms and conditions of the Creative Commons Attribution license (http://creativecommons.org/licenses/by/3.0/). 